Journal of Luminescence 12/13 (1976) 363-368

(c) North-Holland Publishing Company

\title{
TRANSANNULAR INTERACTIONS IN [2.2] PHANES AS STUDIED BY LUMINESCENCE AND OPTICAL DETECTION OF MAGNETIC RESONANCE
}

\author{
D. SCHWEITZER, J.P. COL.PA, K.H. HAUSSER \\ Max-Planck-Institute, Department of Molecular Physics. \\ 6900 Heidelberg, W. Germany
}

M. HAENEL, H.A. STAAB

Heidelberg University, Institute of Organic Chemistry. 6900 Heidelberg, $w$. Germany

\begin{abstract}
Emission spectra of different types of [2.2] naphthalenophanes were measured at $1.25 \mathrm{~K}$ in glasses as well as in small single crystals. In addition, the $D$ and $E$ values of the excited triplet states were studied by optical detection of magnetic resonance in zero field and the results compared with the corresponding monomeres.
\end{abstract}

The investigation of the [2.2] phanes by spectroscopic methods provides information on the transannular intramolecular $\pi$-electron interaction through space, since in these molecules the two aromatic units are kept in a face-to-face arrangement with well defined distance by methylene bridges. Additional information on the influence of the orientation of the two subunits with respect to each other is obtained when studying different isomers of such phanes. The results are relevant as well for the understanding of similar intermolecular interactions in excimers, exc1plexes and charge transfer complexes.

In a first paper [1] we have studied the fluorescence and phosphorescence spectra (at $4.2 \mathrm{~K}$ ) as well as the triplet zero field splitting parameters $D$ and $E$ of several [2.2] phanes in a glass matrix of polymethylmethacrylate (PMMA) and in two cases in fluorene host crystals. We reported results for two naphthalenophanes (connected in 1,4 and 2,6 position), for biphenylophane, phenanthrenophane, tetrahydrophenanthrenophane, dihydrobiphenylophenan threnophane and biphenylophenanthrenophane. The luminescence spectra of these [2.2] phanes show the typical behaviour of emission spectra of dimers or excımers, i.e. broad structureless emission bands shifted to the red as compared to the monomers. This characteristic behaviour is somewhat less marked in the phosphorescence spectra whuch exhibit stıll some structure.

The reduction of the triplet zero field splitting parameters $D$ and $E$ in the [2.2] phanes as compared to the monomers was in the order of $5-20 \%$. This indicates 


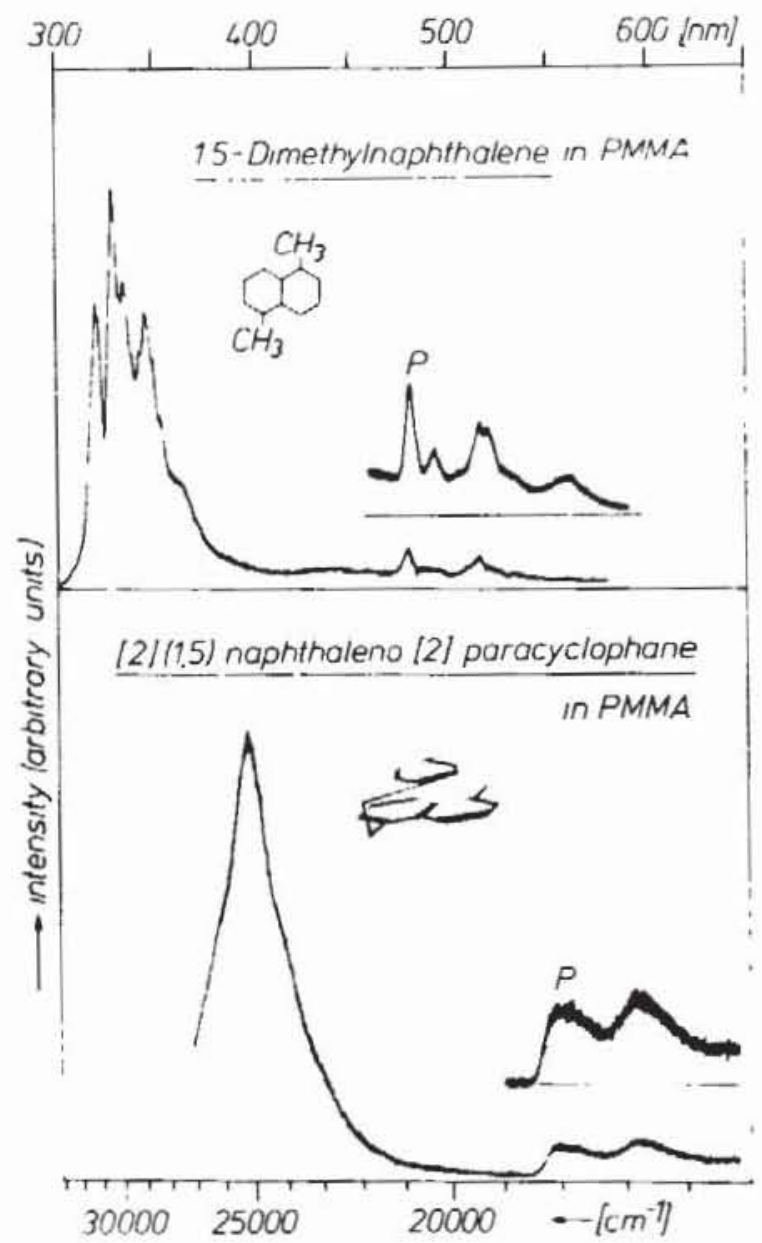

Iig. 1. Luminescence spectra of 1,5-dimethylnaphthalene (on top) and $\{2](1,5)$ naphthaleno[2] paracyclophane in polymethylmethacrylate (PMMA) at $1.25 \mathrm{~K}$. Phosphorescence (P) is also shown separately with higher excitation intensity.

that the two unpared electrons of the excited triplet states have a high probability to be at a given time in the same half of the [2.2] phane, or in other words, that the contribution of an ionic or charge transfer term is rather small.

In this paper we report emission spectra and triplet zero field splitting parameters of [2] (1,5) naphthaleno [2] paracyclophane (1), achiral [2.2] (1,5) naphthalenophane (4), chiral [2.2] $(1,5)$ naphthalenophane (5), and the monomere 1,5-dimethylnaphthalene in a PMMA matrix. Furthermore, we report for the first time results for small crystals of the [2.2] phanes (4) and (5).

The $D$ and $E$ values obtaned with these crystals are still further reduced with respect to the same phanes in PMMA indicating an intermolecular interaction in addition to the intramolecular $\pi$-electron interaction in the isolated phanes.

The preparation and purification of the phanes (4) and (5) was described before [2], while (1) will be reported elsewhere [3]. The PMMA samples were prepared as described in ref. [1]. The zero field splittıng parameters $D$ and $E$ were determined by optical detection of magnetic resonance (ODMR) in zero field.

Fig. 1 shows the fluorescence and phosphorescence emission spectra of 1,5-dl- 
Table 1

$|D|$ and $|E|$ values of $[2.2]$ naphthalenophanes and corresponding monomeres in PMMA (typical error $\pm 0.0002 \mathrm{~cm}^{-1}$ ) and of crystals of achiral and chiral $[2.2\}(1,5)$ naphthalenophanes. Measurements were done by optical detection of magnetic resonance (ODMR) in zero field at $1.25 \mathrm{~K}$.

\begin{tabular}{lcl}
\hline Substances in PMMA & $|E| \mathrm{cm}^{-1}$ & $|D| \mathrm{cm}^{-1}$ \\
\hline 2,6-Dimethylnaphthalene & 0.01555 & 0.0970 \\
1,4-Dimethylnaphthalene & 0.0139 & 0.0961 \\
1,5-Dimethylnaphthalene & 0.01448 & 0.0971 \\
\{2|(1,5) naphthaleno [2] paracyclophane (1) & 0.01484 & 0.08911 \\
[2.2] (2,6) Naphthalenophane (2) & 0.0155 & 0.08925 \\
anti-[2.2](1,4) naphthalenophane (3) & 0.00950 & 0.08656 \\
Achiral [2.2](1,5) naphthalenophane (4) & 0.01443 & 0.08603 \\
Chiral [2.2] (1,5) naphtalenophane (5) & 0.01362 & 0.07380 \\
\hline Crystals & $|E| \mathrm{cm}^{-1}$ & $|D| \mathrm{cm}^{-1}$ \\
\hline Achiral [2.2] (1,5) naphthalenophane (4) & $0.0134 \pm 0.0005$ & $0.0688 \pm 0.0005$ \\
Chiral [2.2] (1,5) naphthalenophane (5) & $0.0130 \pm 0.0005$ & $0.0597 \pm 0.0005$ \\
\hline
\end{tabular}

methylnaphthalene and [2] $(1,5)$ naphthaleno [2] paracyclophane (1) in PMMA at $1.25 \mathrm{~K}$, while fig. 2 shows the emission spectra of the achiral $[2.2](1,5)$ naphthalenophane (4).and the chiral [2.2] (1,5) naphthalenophane (5) in PMMA (on top) as well as the spectra of small crystals of these phanes.

All luminescence spectra of the [2.2] phanes shown here exhbit the typical broad structureless emission bands shifted to the red with some remaining structure in the phosphorescence spectra similar to the one of 1,5-dimethylnaphthalene.

The phosphorescence of the [2.2] phane crystals was very weak. Nevertheless, the microwave transitions between the triplet sublevels could be detected at $6300 \AA$ where the overlapping fluorescence is also weak.

Table 1 shows the triplet zero field splitting parameters $D$ and $E$ of $(1),(4)$ and (5) in PMMA as well as for (4) and (5) in small crystals and for comparison also those of $[2.2](2,6)$ naphthalenophane (2), of anti-[2.2] (1.4) naph thalenophane (3) and of the corresponding monomeric dimethylnaphthalenes.

We consider first the [2] $(1,5)$ naphthaleno [2] paracyclophane (1). For this molecule with two different aromatic units the behaviour is again found to be more sim. ilar to the corresponding aromatic monomere with the lower excited states (here 1,5-dimethylnaphthalene) with some perturbation by the other part of the phane [1].

In distinction to the [2] $\left(4,4^{\prime}\right)$ biphenylo [2] (2.7) phenan threnophane described previously [1], however. the fluorescence is a broad structureless band shifted to the red by about $2500 \mathrm{~cm}^{-1}$ and the phosphorescence is also shifted to the red by about $1500 \mathrm{~cm}^{-1}$ indicating a somewhat stronger coupling between the two aromatic units. 


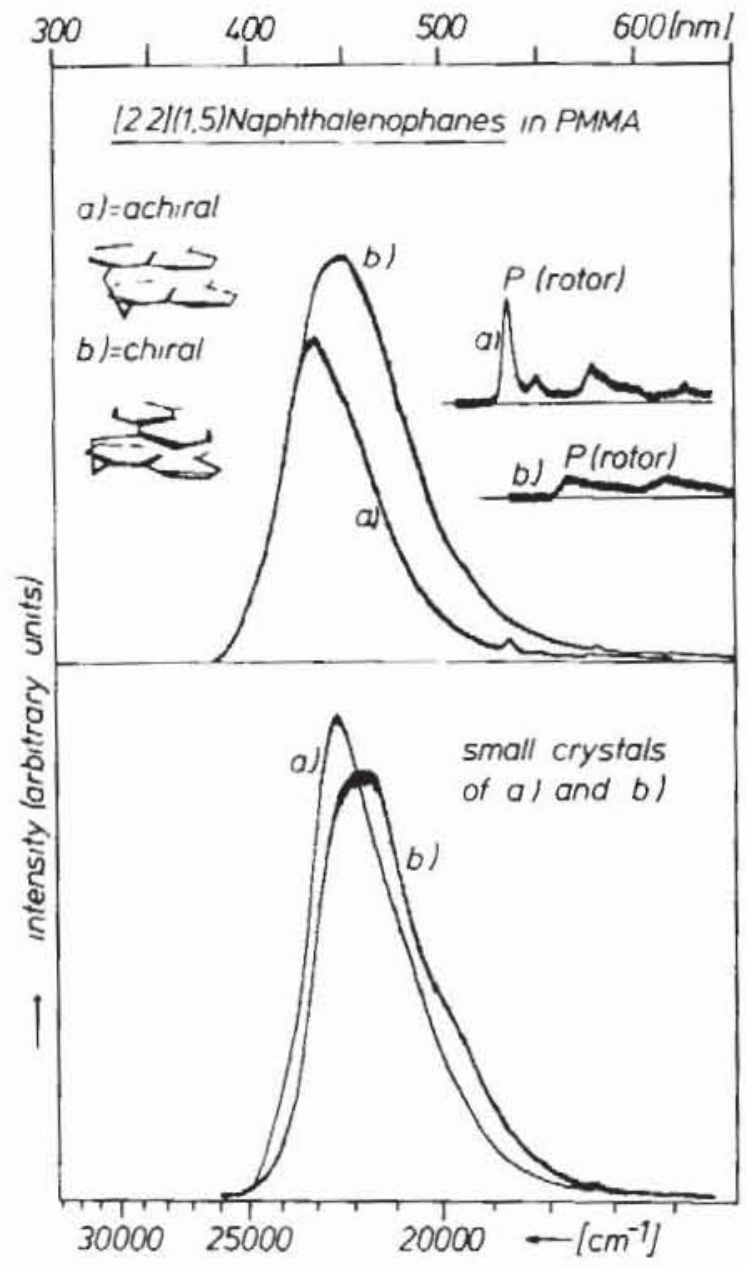

Гig. 2. Luminescence spectra of achural $[2.2](1,5)$ naphthalenophane (a) and chiral $[2.2](1,5)$ naphthalenophane (b) in PMMA (on top) and of small crystals of (a) and (b) at $1.25 \mathrm{~K}$. For the PMMA samples the phosphorescence (P) taken by a rotor is also shown.

The reduction of the zero field splitting parameters is about the same as for [2.2]$(2,6)$ naphthalenophane as compared to 2,6-dimethylnaph thalene [1], which is a case of a weakly coupled [2.2] phane with identical aromatic units.

The red-shift of the fluorescence peak of the [2.2] naphthalenophanes in PMMA with respect to the corresponding dimethylnaphthalenes increases in the sequence $(2,6)-(1,4)-(1,5$ achiral $)-(1,5$ chiral $)$-naph thalenophane by about 4500,5500 , 7000 and $7800 \mathrm{~cm}^{-1}$, respectively, indicatıng an increasing interaction between the two units in this sequence.

An analogue behaviour is also found when observing some features of the triplet states. The phosphorescence of $(2)$ is not shifted to the red with respect to the corresponding monomer, while the red shift of the other phanes increases as the red shift of the fluorescence. The reduction of the $D$ and $E$ values with respect to the corresponding monomers follows the same sequences as well with a minımum reduction of the $D$ values of about $8 \%$ for (2) and a maximum reduction of about $24 \%$ for (5) in PMMA. 
This increase of the interaction of the $\pi$-electrons in the sequence (2), (3), (4), and (5) can be understood as a geometrical basis. We know from $X$-ray studies that the aromatic rings of the phanes deviate considerably from planarity because of strain in the phane system and transannular repulsion of the $\pi$-electrons. Due to energetically more favourable possibility of distributing the deformation upon more $\mathrm{C}-\mathrm{C}$ bonds, the average transannular distance is longer in (2) and hence the overlap is weaker than in the other phanes (3) $-(5)$.

In the small crystals of (4) and (5) the fluorescence is farther shifted to the red as compared to the PMMA samples (fig. 2) and the $D$ values are reduced by another $20 \%$. While this red shift does not exceed typical solvent shifts, the $20 \%$ reduction of the $D$ value indicates to our opinion an intermolecular interaction between adjacent phanes in the crystals in addition to the intramolecular transannular interaction. A different behaviour was also observed in the case of [2.2] $(2,7)$ phenanthrenophane in a fluorene single crystal as compared to the same phane in PMMA where the additional reduction of the $D$ value was about $20 \%$ [1].

It should perhaps be mentioned that the behaviour of the phanes discussed here differs markedly from the one observed with a different type of [2.2] phanes in which one unit forming the phane is a donor and the other unt is an acceptor. 1,4dicyanobenzene and 1,4-dimethoxybenzene, for instance, form the 4,7-dicyano12,15-dimethoxy [2.2] paracyclophanes (pseudo-ortho and pseudo-geminal) [4]. The $D$ values of these charge transfer type phanes are reduced up to a factor of 3 in PMMA and up to a factor of 6 in single crystals as compared to both monomers [5]. This strong reduction of the $D$ values shows that in these charge transfer phanes in distinction to the phanes discussed here, the unpaired electrons have a high probability to be at a given time in different subunits of the phane; we assume that the additional reduction in the single crystals is again due to intermolecular interactions.

\section{References}

[1] D. Schweitzer, J.P. Colpa, J. Behnke, K.H. Hausser, M. Haenel and H.A. Staab, Chem. Phys. 11 (1975) 373.

[2] M. Haenel, Tetrahedron Letters 35 (1974) 3053.

[3] M. Haenel and H.A. Staab, to be published.

[4] V. Taglieber and H.A. Staab, to ve published.

[5] D. Schweitzer, K.H. Hausser, V. Taglieber and H.A. Staab, Chem. Phys., to be published.

\section{Discussion}

J. Tanaka. We have investıgated the fluorescence spectra of several $\{2.2 \mid$ anthracenophanes in cooperation with Professors Visumi and Mataga of Osaka University. The temperature dependence of the fluorescence spectra and also NMR spectra show that significant changes occur from room temperature to low temperature. Have you not experienced similar phenomena in your [2.2] phanes? 
D. Schweitzer: We have not made measurements in solutions, only in glasses (PMMA) and in some cases in crystals. In the temperature range investigated which was from room temperature down to $4.2 \mathrm{~K}$ and in some cases also to $1.25 \mathrm{~K}$ the observed spectra were essentially the same with the exception of the phosphorescence which could not be observed but at $80 \mathrm{~K}$ and below.

J.H. van der Waals: Do you know if the two parts of the molecule perhaps are non-parallel or bent? If so, this would lead to a decrease in $D$, even without the spins spending part of their time on the two different naphthalene nuclei.

D. Schweitzer: The two units of the phane are a little bit bent, but still approximately planar and these planes are parallel to each other. Although this bending would reduce the value of the $D$ parameter it would not explain the same sequence which we observed for the decrease of the $D$ parameter and for the increase of the red shift of the fluorescence and the phosphorescence.

M. Schwoerer: The discussion of the electronic structure of the triplet state from $D$ and $E$ needs the knowledge of their signs. Did you measure the signs of $D$ and $E$ ?

D. Schweitzer: We have only measured the absolute values of the $D$ and $E$ parameters. We do not see any reason why the sign of $D$ and $E$ should change with respect to the monomers in the case of the naphthalenophanes (ref. [1]) in contrast to the charge transfer phanes.

M.A. El-Sayed: Did you determine the relative pumping rates to the different spin levels in these systems and are they anisotropic or isotropic?

D. Schweitzer: We have measured intersystem crossing rates, decay rates and steady state populations. The decay rates are rather different as compared to the monomers and tend to be somewhat less selective and about one order of magnitude shorter. The intersystem crossing rates are also less selective with the evception of the charge-transfer-phanes mentioned at the end. 